\title{
Thermal Analysis of the FSP-1RR Irradiation Test
}

Prepared for the U.S. Department of Energy Assistant Secretary for Nuclear Energy

\section{(V) Westinghouse Hanford Company Richland, Washington}

Hanford Operations and Engineering Contractor for the U.S. Department of Energy under Contract DE-AC06-87RL10930

Copyright License By acceptance of this article, the publisher and/or recipient acknowledges the U.S. Government's right to retain a nonexclusive, royalky-free license in and to any copyright covering this paper. 


\section{DISCLAIMER}

This report was prepared as an account of work sponsored by an agency of the United States Government. Neither the United States Government nor any agency Thereof, nor any of their employees, makes any warranty, express or implied, or assumes any legal liability or responsibility for the accuracy, completeness, or usefulness of any information, apparatus, product, or process disclosed, or represents that its use would not infringe privately owned rights. Reference herein to any specific commercial product, process, or service by trade name, trademark, manufacturer, or otherwise does not necessarily constitute or imply its endorsement, recommendation, or favoring by the United States Government or any agency thereof. The views and opinions of authors expressed herein do not necessarily state or reflect those of the United States Government or any agency thereof. 


\section{DISCLAIMER}

Portions of this document may be illegible in electronic image products. Images are produced from the best available original document. 


\section{Thermal Analysis of the FSP-1RR Irradiation Test}

R. H. Webb

W. F. Lyon III

Date Published

October 14, 1992

To Be Presented at

10th Symposium on

Space Nuclear Power Systems

Albuquerque, New Mexico

January 10-14, 1993

Prepared for the U.S. Department of Energy Assistant Secretary for Nuclear Energy

Copyright License By acceptance of this article, the publisher andior recipient acknowledges the U.S. Government's right to retain a nonexclusive, royalty-free license in and to any copyright covering this paper. 


\section{LEGAL DISCLAIMER}

This report was prepared as an account of work sponsored by an agency of the United States Government. Neither the United States Government nor any agency thereof, nor any of their employees, nor any of their contractors, subcontractors or their employees, makes any warranty, express or implied, or assumes any legal liability or responsibility for the accuracy, completeness, or any third party's use or the results of such use of any information, apparatus, product, or process disclosed, or represents that its use would not infringe privately owned rights. Reference herein to any specific commercial product, process, or service by trade name, trademark, manufacturer, or otherwise, does not necessarily constitute or imply its endorsement, recommendation, or favoring by the United States Government or any agency thereof or its contractors or subcontractors. The views and opinions of authors expressed herein do not necessarily state or reflect those of the United States Government or any agency thereof.

This report has been reproduced from the best available copy.

Printed in the United States of America

DISCLM-2.CHP (1-91) 
THERMAL ANALYSIS OF THE FSP-1RR IRRADIATION TEST.

Roger H. Webb and William F. Lyon III

Westinghouse Hanford Company

P. O. Box 1970, Mail Stop L5-02

Richland, WA 99352

(509) 376-9966

CAMERA READY MANUSCRIPT prepared for:

Tenth Symposium

on Space Nuclear Power Systems

Albuquerque, New Mexico

10-14 January 1993

initial submission: 10 August 1992

final submission: $\quad 16$ October 1992

Author to whom correspondence should be sent: Roger H. Webb 


\title{
THERMAL ANALYSIS OF THE FSP-1RR IRRADIATION TEST
}

\author{
Roger H. Webb and William F. Lyon III \\ Westinghouse Hanford Company \\ P. O. Box 1970, Mail Stop L5-02 \\ Richland, WA 99352
}

(509) $376-9966$

\begin{abstract}
The thermal analysis of four unirradiated fuel pins to be tested in the FSP-1RR fuels irradiation experiment was completed. This test is a follow-on experiment in the series of fuel pin irradiation tests conducted by the SP-100 Program in the Fast Flux Test Facility. One of the pins contains several meltwire temperature monitors within the fuel and the $\mathrm{Li}$ annulus. A post-irradiation examination will verify the accuracy of the pre-irradiation thermal analysis. The purpose of the pre-irradiation analysis was to determine the appropriate insulating gap gas compositions required to provide the design goal cladding operating temperatures and to ensure that the meitwire temperature ranges in the temperature monitored pin bracket peak irradiation temperatures. This paper discusses the methodology and summarizes the results of the analysis.
\end{abstract}

\section{INTRODUCTION}

Fuel pin irradiation tests have been conducted over the past several years in the Fast Flux Test Facility (FFTF) and Experimental Breeder Reactor-II (EBR-II) in support of the SP-100 Program (Makenas et al. 1991). These tests have irradiated 86 fuel pins. Although post-irradiation examinations (PIE) have been conducted on many of these pins, there has been no way to determine the actual irradiation temperatures and thus verify the temperature predictions made from pre-irradiation thermal analyses. Verification of the operating temperatures is necessary because uncertainties in calculational input parameters (i.e., characterization of power, flux, etc.) contribute to a modest level of uncertainty in the calculation of fuel pin temperatures.

The FSP-1RR test is a reconstituted fuel assembly that includes four new fuel pins. One of the new pins contains passive temperature monitors positioned axially within annular fuel pellets and in the $\mathrm{Li}$ annulus between the cladding and the Ti-Zr-Mo (TZM) subcapsule. The PIE of this pin will determine peak irradiation temperatures and verify the accuracy of the pre-irradiation thermal analysis methodology used for all SP-100 fuels tests. The purpose of this paper is to (1) briefly describe the FSP-IRR test, (2) describe in general the pre-irradiation thermal analyses performed on the four new pins, and (3) discuss in detail the significance of the temperature monitored fuel pin and present the results of the pre-irradiation thermal analyses.

\section{BACKGROUND}

The FSP series of fuel pin experiments have been irradiated in the FFTF. The fuel pin experiments each consist of 1 test assembly containing 19 fuel assemblies. Each fuel assembly contains two test pins. A schematic diagram of a typical FSP series fuel assembly is shown in Figure 1. The most recent experiments have been conducted to provide the performance data on UN fuel with $\mathrm{Nb}-1 \% \mathrm{Zr}$ cladding and Re diffusion barriers in support of the SP-100 Generic Flight System. The initial test, FSP-1, completed irradiation in 1989 and reached 2.5 at. \% peak fuel burnup. The test assembly was then reconstituted into FSP-1R by replacing eight irradiated fuel assemblies with fresh fuel assemblies. The 16 irradiated pins were removed from the assemblies for nondestructive and destructive examinations. FSP-1R completed irradiation after approximately 400 equivalent full power days (EFPD) in September 1991. This test reached 3.4 and 5.6 at. \% peak burnup for the FSP-1R and FSP-1 pins, respectively. Six fuel assemblies will be replaced with four simulated and two active fuel assemblies containing four fresh fuel pins for the FSP-1RR experiment. The goals of the FSP-1RR experiment are to (1) evaluate enhanced fuel/cladding mechanical interaction, (2) physically determine fuel pellet and Li annulus operating temperatures, (3) assess the compatibility of $\mathrm{BeO}$ axial reflectors with other components within the fuel pin, and (4) extend the burnup of previously irradiated fuel pins an additional 3.4 at. \%. 


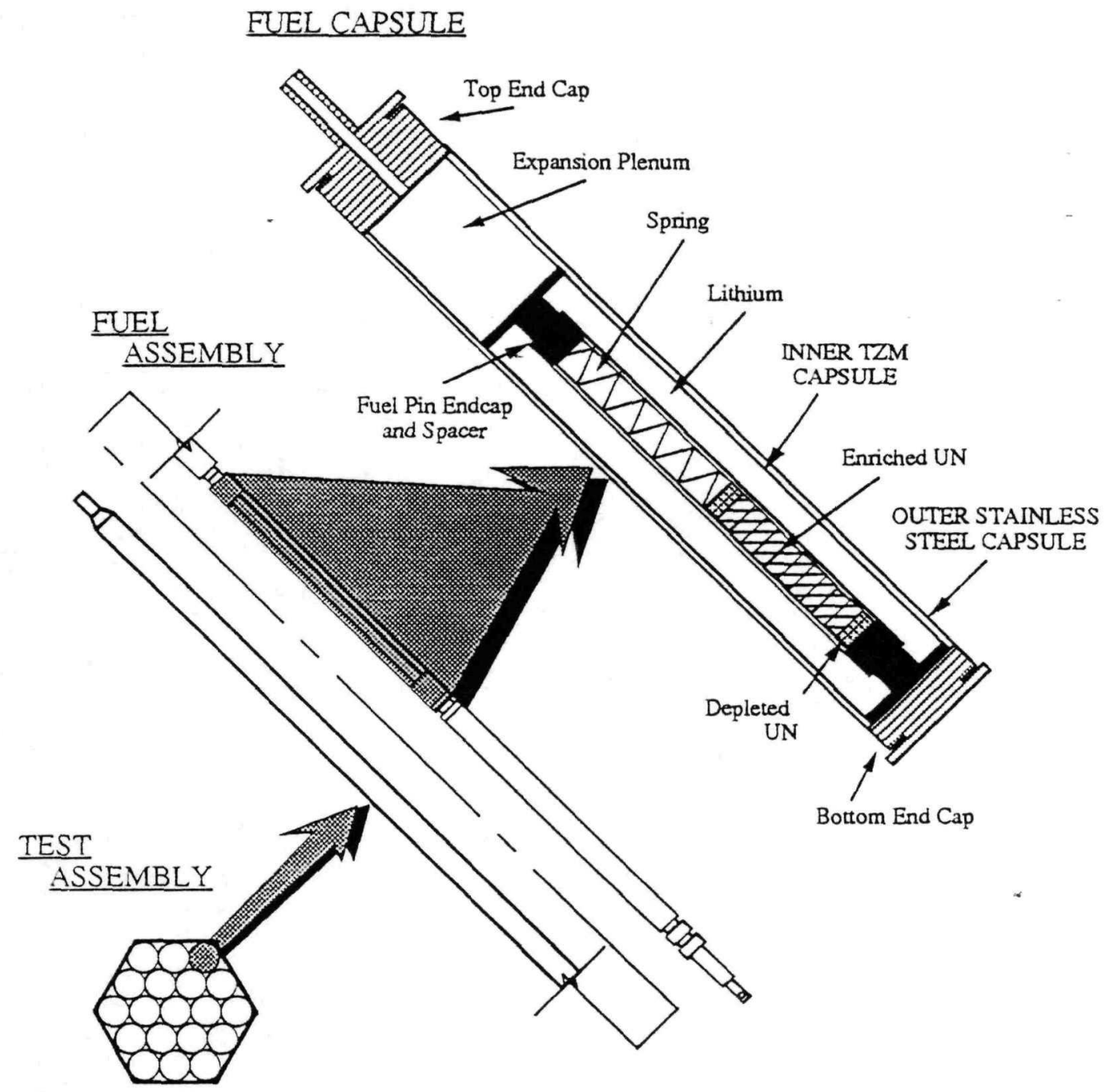

FIGURE 1. SP-100 FSP Series Fuel Assembly Schematic.

\section{EXPERIMENT DESCRIPTION}

Each fuel assembly contains two encapsulated UN fuel pins placed one above the other. The pins are placed in $\mathrm{Li}$ and isolated by multiple concentric capsules. The operating temperature of each pin is individually set by using a specific composition of a He/Ar gas mixture in the gap between the inner TZM capsule and the outer stainless steel capsule.

The four new fuel pins to be included in FSP-1RR have approximately $15-\mathrm{cm}$ fuel columns of UN ( $21 \%$ enriched ${ }^{23} \mathrm{U}$ ) with $\mathrm{Re}$ liners bonded to $\mathrm{Nb}-1 \% \mathrm{Zr}$ cladding. The pins also include Re thimbles or disks placed at the top and bottom of the pin to test their effectiveness in mitigating $\mathrm{N}_{2}$ migration from the fuel to the $\mathrm{Nb}-1 \% \mathrm{Zr}$ endcaps. The cladding operating temperatures are targeted at $1400 \mathrm{~K}$. Table 1 provides a summary of the FSP-1RR fuel pin design.

While all pins are of standard design, two of the four new pins have approximately $5 \mathrm{~cm}$ of BeO pellets at the lower end of the fuel stack (one each of $85 \%$ and $95 \%$ BeO theoretical density) to act as an axial neutron reflector. This axial reflector region is separated from the fuel column by a small Re disk. The PIE of these pins will determine the extent of reaction and/or migration of species between the fuel and reflector regions in the reference operating temperature regime. 
TABLE 1. FSP-1RR Standard Fuel Pin Design Parameters.

\begin{tabular}{lc}
\hline Number of Fuel Pins & 4 \\
Cladding Material & $\mathrm{Nb}-1 \% \mathrm{Zr}$ \\
Liner Material & $\mathrm{Re}$ \\
Pin Length & $33 \mathrm{~cm}$ \\
Pin Outer Diameter & $0.693 \mathrm{~cm}$ \\
Fuel Material & $\mathrm{UN}$ \\
Fuel Column Length & $15.24 \mathrm{~cm}$ \\
UN Fuel Density & $96 \%$
\end{tabular}

One of the pins was fabricated with larger diameter fuel pellets, which reduces the fuel/cladding diametral gap from $0.013 \mathrm{~cm}$ to $0.005 \mathrm{~cm}$. The PIE of this pin will allow the evaluation of mechanical interaction between the fuel and the Re-bonded, $\mathrm{Nb}-1 \% \mathrm{Zr}$ cladding.

The fourth pin contains temperature monitors comprised of encapsulated meltwires. These meltwires are composed of either metals or alloys that provide a range of melting temperatures. Table 2 lists the meltwire alloy compositions and their associated melting temperatures. The meltwires were selected so that some of the temperature monitors will be meited and some will be left intact allowing them to bracket the peak irradiation temperatures in the monitored positions.

TABLE 2. Meltwire Alloys and Associated Melting Temperatures.

\begin{tabular}{cc}
$\begin{array}{c}\text { Meltwire Material, } \\
\text { Nominal Wt. \% }\end{array}$ & $\begin{array}{c}\text { Nominal Meltwire } \\
\text { Melting Temperature, }{ }^{\circ} \mathrm{K}\end{array}$ \\
\hline $\mathrm{Pd}^{1}$ & 1827 \\
$\mathrm{Fe}^{1,2}$ & 1808 \\
$\mathrm{Ni}^{1.2}$ & 1728 \\
$88 \mathrm{Pd}-12 \mathrm{Cu}^{1,2}$ & 1683 \\
$77 \mathrm{Pd}-23 \mathrm{Cu}^{1,2}$ & 1578 \\
$60 \mathrm{Pd}-40 \mathrm{Ni}^{2}$ & 1518 \\
$60 \mathrm{Pd}-40 \mathrm{Cu}^{3}$ & 1478 \\
$27 \mathrm{Pd}-73 \mathrm{Mn}^{3}$ & 1420 \\
$\mathrm{Cu}^{3}$ & 1356 \\
$\mathrm{Nd}^{3}$ & 1297 \\
\hline
\end{tabular}

1 - Meltwires in upper annular fuel pellet region.

2 - Meltwires in lower annular fuel pellet region.

3 - Meltwires in $\mathrm{Li}$ annulus region.

Figure 2 is a cross-sectional schematic of the temperature monitor pin illustrating the locations of the monitors. Fuel pellets are numbered for identification. Temperature monitors are placed within annular fuel pellets in the fuel column and also within the $\mathrm{Li}$ annulus suspended in a thimble from a thin wire stretched between the fuel pin spacers. Fuel pellets 7 and 16 are annular so that they can accommodate any axial expansion of the temperature monitors.

The new fuel assemblies for FSP-1RR are fabricated and are awaiting reconstitution. Figure 3 is a photograph of the fuel pins before placement in their TZM capsules. The top pin is the temperature monitor pin. The Li annulus temperature monitors can be seen positioned by a wire attached to the radial spacers. Figure 4 is a radiograph of the reduced gap pin and the temperature monitor pin encapsulated in their respective fuel capsules. The pins are placed in Li filled TZM capsules. The temperature monitor fuel capsule will be positioned above the reduced-gap fuel capsule in a stainless steel tube to create an individual fuel assembly as shown in Figure 1. 


\section{MODEL CONFIGURATION AND DEVELOPMENT}

The FSP-1RR thermal analyses were performed using the TEMPEST N32 code (Trent and Eyler 1989). TEMPEST is a transient, three-dimensional, finite difference, hydrothermal computer program designed to analyze a broad range of coupled fluid dynamic and heat transfer systems. Similar thermal analyses were performed for the original design of the FSP-1 experiment. Follow-on studies of selected FSP-1 irradiated pins have demonstrated the capability of this modeling technique to identify physical phenomenon observed in PIE (Lyon 1991). Specifically, analyses were able to predict the location of irradiation-induced swelling in the cladding plenum region of irradiated pins.

Individual fuel capsules were modeled with the geometry and material properties appropriate for each pin. The material properties for the structural components and fuel were evaluated at a constant temperature representative of in-core operating conditions. The average heat generation rates were derived from reactor physics analyses performed in support of FSP-1RR (Knutson 1992). Heat generation rates accommodated heating from interaction with gamma rays and neutrons for nonfissioning materials. These calculations also included adjustments for the radial and axial location of the experiment in core, probable core power, and end-of-cycle conditions. The reactor coolant temperatures corresponding to the axial and radial test pin locations within the FSP-1RR assembly were used as the external boundary conditions. These sodium temperatures were obtained from thermal-hydraulic analyses of the FSP-1RR test assembly using the SUPERENERGY -2 code (Basehore and Todreas 1980).

The gas composition required to achieve the design cladding midwall temperature of $1400 \mathrm{~K}$ was obtained by parametric analyses varying only the gap gas composition. Peak cladding midwall temperatures are calculated to $1400 \pm 15 \mathrm{~K}$ as stated in the design specifications. Gas composition was varied only by increments of $0.5 \% \mathrm{He} / \mathrm{Ar}$ because of commercial gas mixture availability. The gas composition increment was small enough to adequately achieve goal temperatures. Separate calculations were made for the temperature monitor pin. Peak operating temperatures in this pin in the monitored regions is to be bracketed by the temperature range of the monitors.

\section{RESULTS}

The results of the analysis provided detailed temperature and $\mathrm{Li}$ velocity distributions for all four pins. Calculated fluid velocities confirmed laminar flow within the $\mathrm{Li}$ annulus for all four new pins.

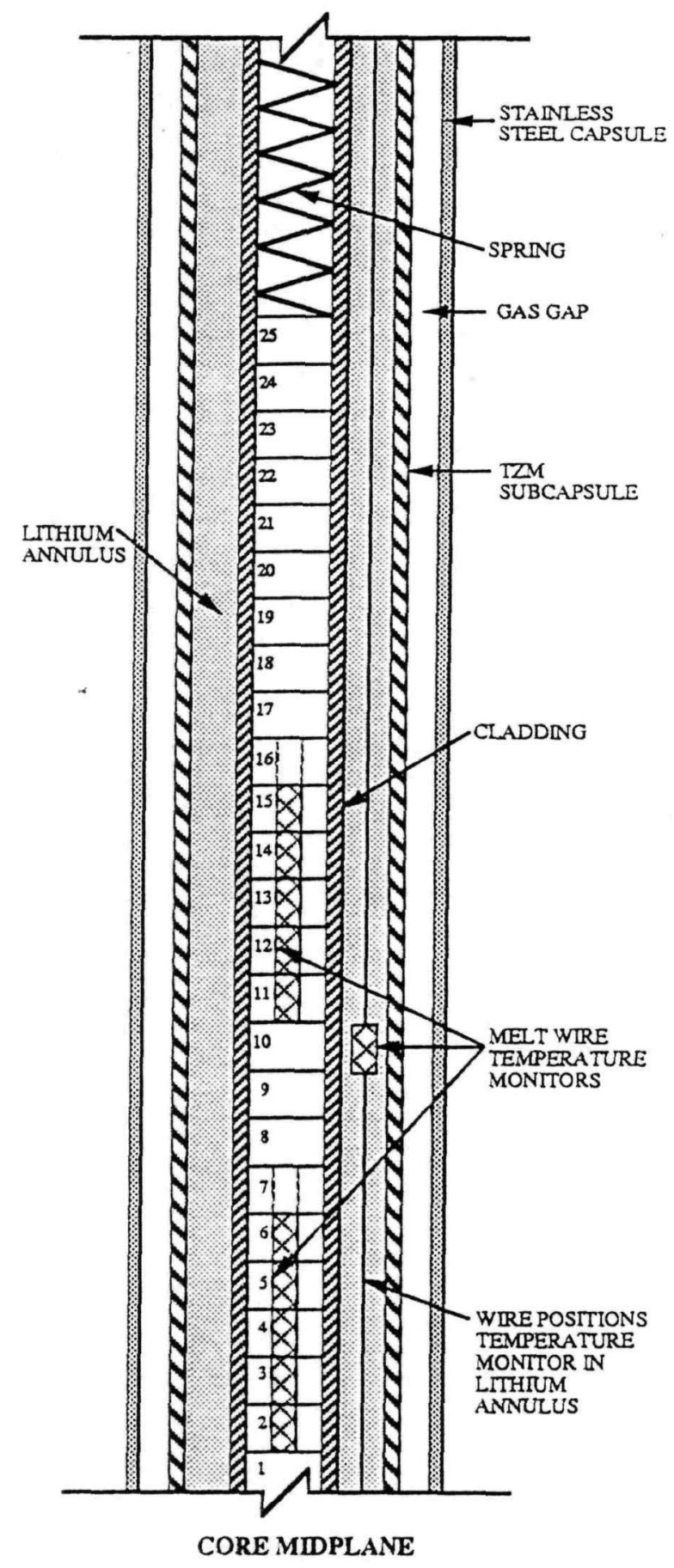

FIGURE 2. Simplified Cross-Section of the Temperature Monitor Pin (fuel pellets are numbered). 
Figure 5 illustrates typical data obtained from TEMPEST calculations for the fuel pin with temperature monitors. The plot shown is a two-dimensional cross-section of the pin with physical details overlaid on the temperature distribution from the fuel centerline to beyond the outer stainless steel capsule.


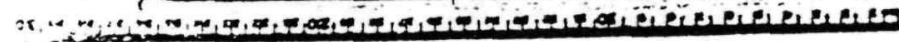

FIGURE 3. FSP-1RR Fresh Pins and TZM Capsules.

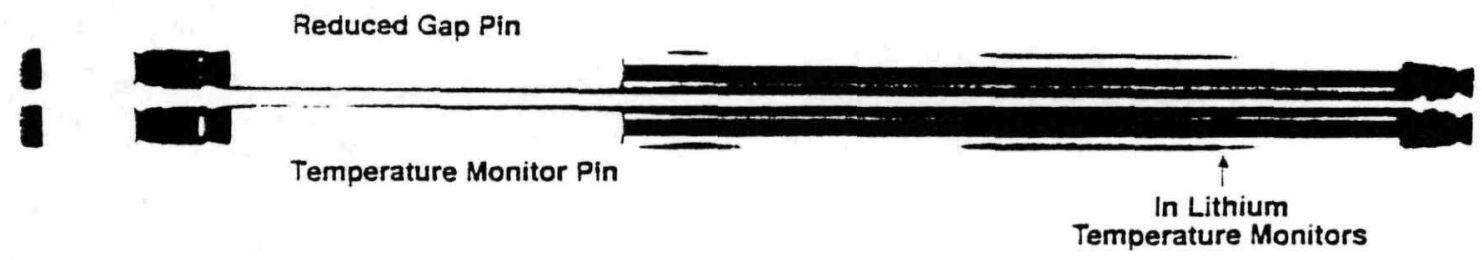

FIGURE 4. Radiographs of Encapsulated Reduced Gap and Temperature Monitor Pins.

Table 3 summarizes the gas compositions calculated to provide the peak cladding midwall design temperature of $1400 \mathrm{~K}$. The effect of changes in gas mixture composition and capsule gap thickness are summarized for each fuel pin in Table 4. Typically, a $1 \%$ change in gas composition results in an $8 \mathrm{~K}$ temperature change. The effect of gap thickness varies from $70 \mathrm{~K} / \mathrm{mm}$ to just above $100 \mathrm{~K} / \mathrm{mm}$ depending primarily on pin power. Two gas mixtures were used for the actual fabrication of the fuel capsules, $67 \% \mathrm{He} / 33 \% \mathrm{Ar}$ for the temperature monitor pin and $75.5 \% \mathrm{He} / 24.5 \% \mathrm{Ar}$ for the remaining three pins. The $75.5 \% \mathrm{He} / 24.5 \% \mathrm{Ar}$ gas composition allows the three pins to achieve the predicted peak temperatures within the $15 \mathrm{~K}$ experiment criteria. The gas mixture used for the temperature monitor pin permits monitors to adequately bracket the peak irradiation temperatures in the monitored region as seen in Figure 6. A peak cladding midwall temperature of $1437 \mathrm{~K}$ is slightly higher than the goal temperature, but is acceptable. 


\section{CONCLUSIONS}

The thermal analysis of the fresh fuel pins to be placed into the FSP-1RR experiment was completed using the techniques developed for previous fuel capsule analyses. The PIE of the temperature monitor pin will physically determine the peak operating temperatures of the fuel column, as well as the $\mathrm{Li}$ annulus. This will allow confirmation and/or calibration of the thermal analysis models. Verification of the thermal analysis will confirm the accuracy of the thermal analyses performed on previously irradiated pins.

The goal of the analysis was to determine the required insulating gas mixtures that would meet the stated operational goals. Calculations were completed with the TEMPEST code that defined the required gas compositions to meet the peak cladding midwall temperature criterion. The calculations were then revised to reflect (1) adjustments in the operational regime of the temperature monitor pin to better match the temperature monitor ranges, and (2) actual fuel capsule gas loadings.

The FSP-1RR experiment is extremely valuable to the program because of its ability to confirm preirradiation thermal analyses. Finat assembly of this test is on hold because of the U.S. Department of Energy's recent decision to place the FFTF in a standby mode. The project is considering redesigning the FSP-1RR test for irradiation in EBR-II so that temperature data can be obtained to validate the models used in the design and analysis of the 86 fuel pins previously irradiated in support of SP-100 UN fuel development.

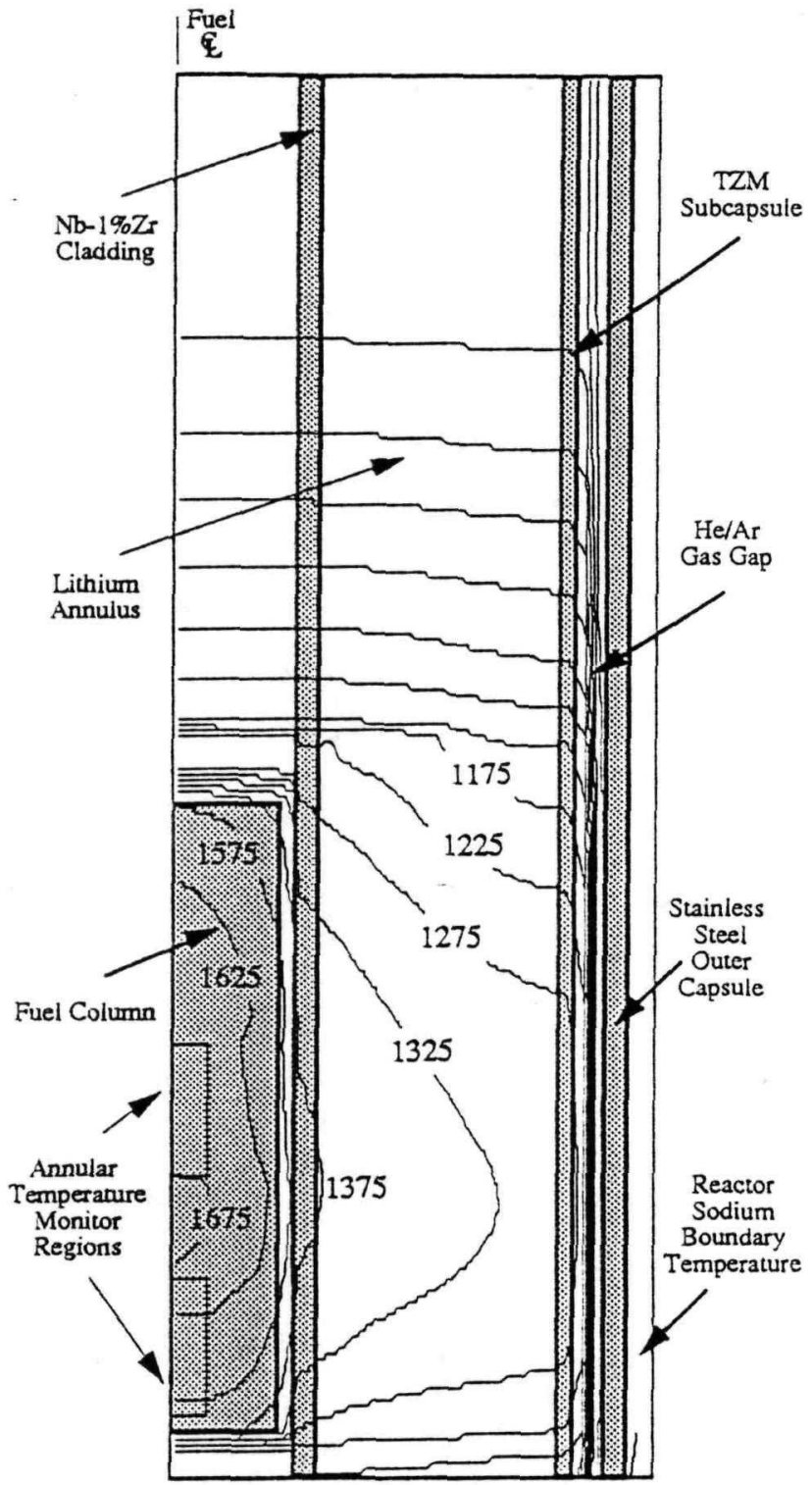

FIGURE 5. Temperature Monitor

Pin Components and

Temperature (K) Contours.

TABLE 3. FSP-1RR Gap Gas Composition Summary.

\begin{tabular}{ccccc}
\hline & $\begin{array}{c}\text { Temperature } \\
\text { Monitor Pin }\end{array}$ & $\begin{array}{c}\text { Reduced Gap } \\
\text { Pin }\end{array}$ & $\begin{array}{c}\text { BeO Pin } \\
(85 \% \text { TD })\end{array}$ & $\begin{array}{c}\text { BeO Pin } \\
(95 \% \text { TD })\end{array}$ \\
\hline He \% & 71.5 & 75.5 & 73.5 & 74 \\
Ar \% & 28.5 & 24.5 & 26.5 & 26 \\
\hline
\end{tabular}

Note: All compositions were designed to provide $1400 \mathrm{~K}$ peak cladding midwall temperatures. To optimize the meltwire temperature ranges, the recommended gap gas mixture for the temperature monitor pin is $67 \% \mathrm{He} / 33 \%$ Ar (which yields a calculated peak cladding midwall temperature of $1437 \mathrm{~K}$ ). 
TABLE 4. Gas Gap Composition and Gap Thickness Effects on Peak Cladding Midwall Temperature.

\begin{tabular}{ccccc}
\hline & $\begin{array}{c}\text { Temperature } \\
\text { Monitor Pin }\end{array}$ & $\begin{array}{l}\text { Reduced } \\
\text { Gap Pin }\end{array}$ & $\begin{array}{l}\text { BeO Pin } \\
(85 \% \text { TD })\end{array}$ & $\begin{array}{l}\text { BeO Pin } \\
\text { (95\% TD) }\end{array}$ \\
\hline $\begin{array}{c}\text { Gas } \\
\begin{array}{c}\text { Composition } \\
(\mathrm{K} / \% \text { change in } \\
\text { gas composition) }\end{array}\end{array}$ & 7.71 & 8.02 & 8.14 & 8.07 \\
$\begin{array}{c}\text { Gap Thickness } \\
(\mathrm{K} / \mathrm{mm})\end{array}$ & 98.8 & 102.4 & 106.7 & 70.5 \\
\hline
\end{tabular}

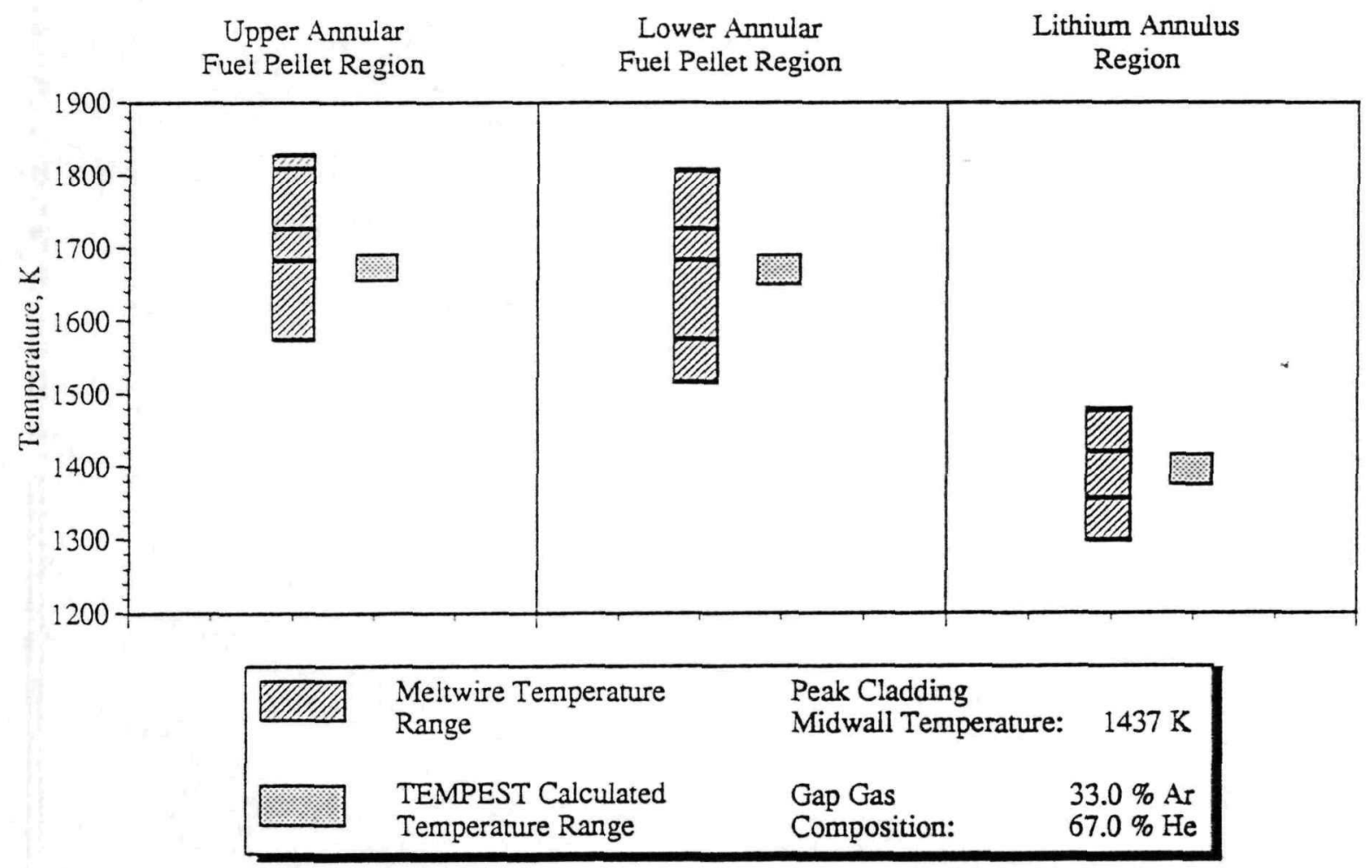

FIGURE 6. Meltwire Temperature Ranges as Compared to Predicted Fuel and Lithium Temperatures in the Temperature Monitor Pin.

\section{Acknowledgments}

The SP-100 fuels and materials irradiation testing program is an interlaboratory effort supported by the U.S. Department of Energy and the National Aeronautics and Space Administration. The construction, performance, and examination of the tests are conducted by Westinghouse Hanford Company under Contract No. DE-ACO6-87RL10930. Additionally, the authors would like to recognize the contributions of L. M. McWethy and B. J. Knutson of Westinghouse Hanford Company and D. S. Trent and L. L. Eyler of Battelle Pacific Northwest Laboratory. 


\section{References}

Basehore, K. L. and N. E. Todreas (1980) SUPERENERGY-2: A Multiassembly, Steady-State Computer Code for LMFBR Core Thermal-Hydraulic Analysis, PNL-3379, Battelle Pacific Northwest Laboratory, Richland, WA.

Lyon, W. F. (1991) "Thermal Analysis of the FSP-1 Fuel Pin Irradiation Test," in Trans. 8th Symposium on Space Nuclear Power Systems, CONF-910116-Summs., Albuquerque, NM, 6-10 January 1991.

Knutson, B. J. (1992) Internal memo to D. B. Graves, Westinghouse Hanford Company, Richland, WA, 22 January 1992.

Makenas, B. J., J. W. Hales, and A. L. Ward (1991), "Fuels Pin Irradiation Testing for the SP-100 Program, " in Trans. 8th Symposium on Space Nuclear Power Systems, CONF-910116-Summs., Albuquerque, NM, 6-10 January 1991.

Trent, D. S. and L. L. Eyler (1989), TEMPEST: A Three-Dimensional Time-Dependent Computer Program for Hydrothermal Analysis, PNL-4348, Volume 1, Rev. 2, Battelle Pacific Northwest Laboratory, Richland, WA. 